\title{
Quantification of the internal space climate
}

\author{
Peter Häupl ${ }^{1}$, and Frank Hansel $^{2}$ \\ ${ }^{1}$ Prof. (em) Dr.-Ing. habil., Dresden University of Technology, Dresden, Germany \\ ${ }^{2}$ Dipl.-Ing. (FH), Brandenburg University of Technology, Cottbus, Germany
}

\begin{abstract}
A practicable model and program CLIMT is put forward for determining the hourly values of indoor air temperature and the interior air humidity in relation to the external climate, the building parameters (geometry, material properties), the ventilation and the use of the internal space (interior heat sources, moisture sources and heating system). In order to generate the outdoor climatic dates (temperature, relative humidity, short and long wave radiation, precipitation, wind velocity and direction, driving rain) for the simulation a climate generator CLIG has been developed additionally. The results have been validated with measurements in actual buildings.
\end{abstract}

\section{Introduction and climate boundary conditions}

The developed simplified model and program CLIMT (Climate-Indoor-MoistureTemperature) can be used for the calculation of the indoor climate components consisting of air temperature and air relative humidity [1,2]. At first it is necessary to provide the hourly values of the outdoor climate. Secondly, the geometry of the building, the construction of the building parts and the thermic and hygric material parameters must be given. Finally, all parameters of use - heating, inner heat and moisture sources, ventilation and the shadow equipment are necessary.

Before the energy and moisture balances for the internal space of the building are formulated, the set of outer climate components (here climate of the German city Dresden 1997, table 1) has been completed. The columns in the table 1 mean: 0Number of hours, 1-Temperature in ${ }^{\circ} \mathrm{C}$, 2-Relative humidity in $\%$, 3-Diffuse radiation in $\mathrm{W} / \mathrm{m}^{2}$, 4-Direct radiation in $\mathrm{W} / \mathrm{m}^{2}, 5$-Precipitation in $\mathrm{mm} / \mathrm{h}, 6$-Wind velocity in $\mathrm{m} / \mathrm{s}, 7-\mathrm{Wind}$ direction in ${ }^{\circ}$. The temperature and relative humidity can be used directly. The direct and diffuse short wave radiation on the arbitrary outside surface have to calculate with all relevant angles (solar altitude, orientation of building, self shading). The long wave radiation results by means of the direct and diffuse shortwave radiation (cloud coverage) and the relative humidity. 
Table 1. Outdoor climate ( 8760 hourly values) of Dresden, measurement 1997, extraction $4944 \mathrm{~h}$ to $4959 \mathrm{~h}$ (July) values in the MATHCAD format.

\begin{tabular}{|c|c|c|c|c|c|c|c|c|}
\hline & 0 & 1 & 2 & 3 & 4 & 5 & 6 & 7 \\
\hline 4944 & $4.944 \cdot 10^{3}$ & 15.8 & 96.01 & 0 & 0 & 0 & 2.5 & 288.2 \\
\hline 4945 & $4.945 \cdot 10^{3}$ & 15.68 & 96.01 & 0 & 0 & 0 & 2.9 & 291.94 \\
\hline 4946 & $4.946 \cdot 10^{3}$ & 15.55 & 96.02 & 0 & 0 & 0 & 3 & 289.96 \\
\hline 4947 & $4.947 \cdot 10^{3}$ & 15.5 & 95.82 & 0 & 0 & 0 & 3.3 & 291.06 \\
\hline 4948 & $4.948 \cdot 10^{3}$ & 15.57 & 94.01 & 0 & 0 & 0 & 3.7 & 288.86 \\
\hline 4949 & $4.949 \cdot 10^{3}$ & 15.52 & 93.33 & 0 & 0 & 0 & 3.2 & 297.99 \\
\hline 4950 & $4.95 \cdot 10^{3}$ & 15.23 & 93.74 & 1.12 & 3.13 & 0 & 3.6 & 289.96 \\
\hline 4951 & $4.951 \cdot 10^{3}$ & 15.05 & 94.3 & 3.2 & 25.02 & 0 & 4.5 & 287.54 \\
\hline 4952 & $4.952 \cdot 10^{3}$ & 15.09 & 93.9 & 3.74 & 31.64 & 0 & 4.6 & 293.92 \\
\hline 4953 & $4.953 \cdot 10^{3}$ & 15.18 & 94.3 & 0.6 & 76.99 & 13 & 4.1 & 290.18 \\
\hline 4954 & $4.954 \cdot 10^{3}$ & 16.06 & 90.14 & 8.48 & 125.1 & 0 & 5.2 & 290.18 \\
\hline 4955 & $4.955 \cdot 10^{3}$ & 16.78 & 81.51 & 20.04 & 142.3 & 0 & 5.9 & 282.92 \\
\hline 4956 & $4.956 \cdot 10^{3}$ & 17.38 & 77.88 & 16.88 & 123.8 & 0 & 4.7 & 290.29 \\
\hline 4957 & $4.957 \cdot 10^{3}$ & 18.56 & 71.3 & 40.43 & 251.2 & 0 & 4.7 & 281.6 \\
\hline 4958 & $4.958 \cdot 10^{3}$ & 20.18 & 62.19 & 82.21 & 304.6 & 0 & 4.4 & 275.55 \\
\hline 4959 & $4.959 \cdot 10^{3}$ & 19.8 & 59.88 & 38.16 & 213.6 & 0 & 7.1 & 280.17 \\
\hline
\end{tabular}

For the driving rain on the vertical building parts has been developed an own model [1] by means of the column 5 to 7 and the orientation of the building. For the calculation of all hourly values has been written the $\mathrm{C}++$ program CLIG (climatic generator) [3]. Fig. 1 shows the input mask with minicharts of thermic results. Figure 2 illustrates any thermic climatic values for Dresden between April 23th and 26th 1997. The green graph in Fig. 2 (e.g. shortwave radiation on the East wall) shows in the morning a high value (direct and diffuse radiation) and in the afternoon a low level (diffuse radiation only in consequence of the self shading effect).

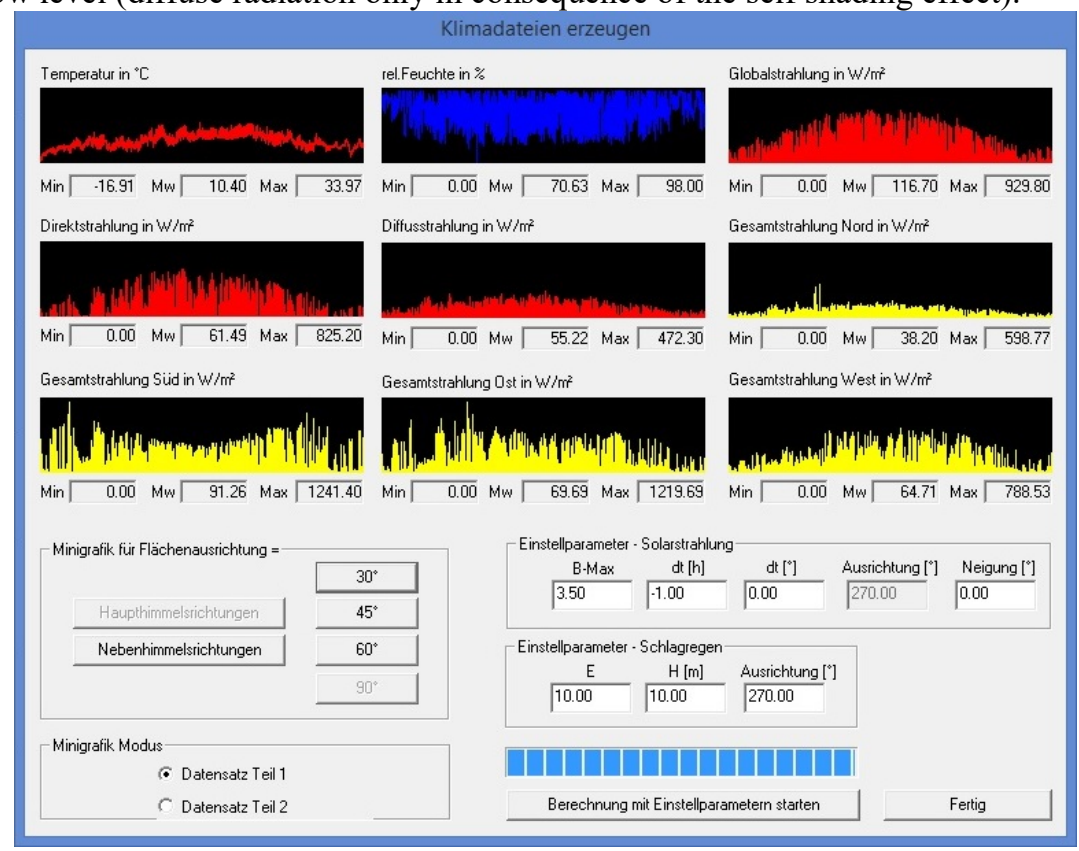

Fig. 1. CLIG Input mask with minicharts of thermical results. 


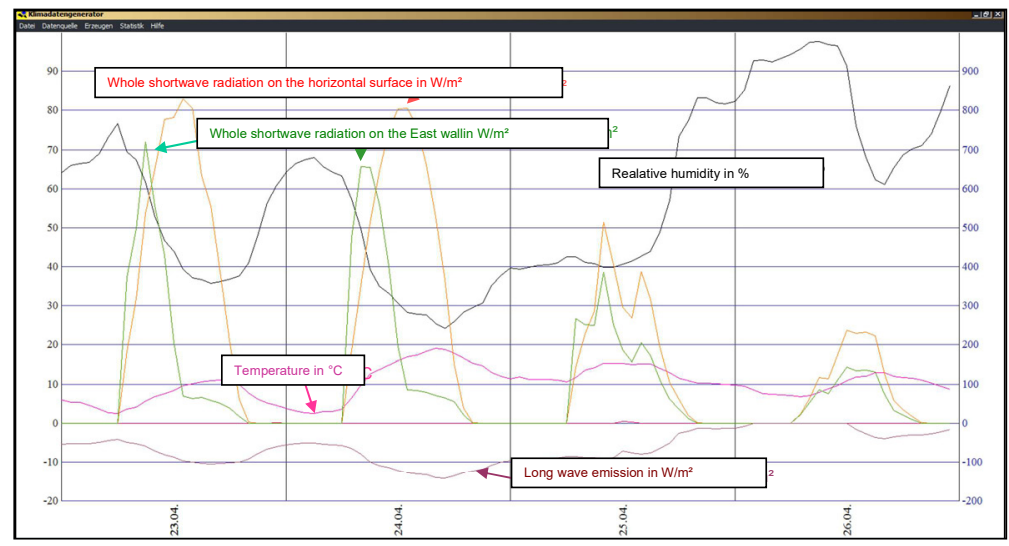

Fig. 2. Temperature, relative humidity (left coordinate axis), whole short wave radiation shortwave radiaton on the East wall and long wave radiation (right coordinate axis), Dresden from April 23th to 26th.

\section{Modelling of the energy balances of the indoor room}

The first version of the model and program has been described in [2]. Fig. 3 illustrates the thermic balance system of equations for the calculation of the outer surface temperature, the inner surface temperature and the indoor air temperature.

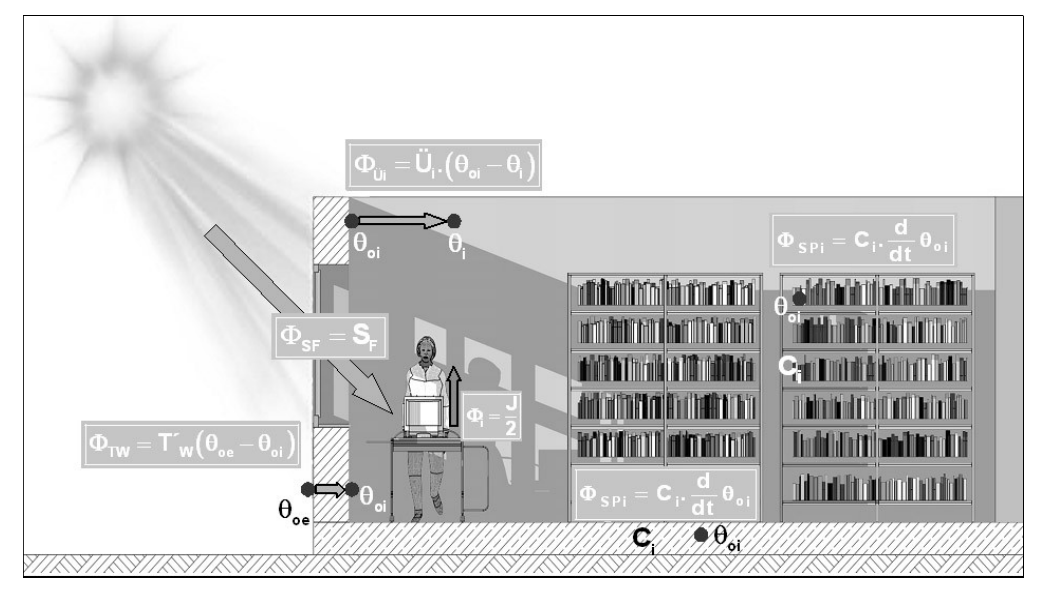

Fig. 3. Energy balances of the interior of the house.

Energy balance of the outer surfaces

$$
S_{W}=T_{W}^{\prime} \cdot\left(\theta_{o e}-\theta_{o i}\right)+\ddot{U}_{e} \cdot\left(\theta_{o e}-\theta_{e}\right)+C_{e} \cdot \frac{d \theta_{o e}}{d t}
$$

Energy balance of the indoor air volume, $\mathrm{J} / 2$ indoor heat sources versus convection

$$
0=\left(L+T_{F}\right) \cdot\left(\theta_{e}-\theta_{i}\right)+\ddot{U}_{i} \cdot\left(\theta_{o i}-\theta_{i}\right)+\frac{J}{2}
$$

Energy balance of the inner surfaces, $\mathrm{J} / 2$ indoor heat sources versus radiation 


$$
\iota_{i} \cdot \frac{}{d t}=\nu_{F}+\Lambda_{W} \cdot\left(\sigma_{o e}-\sigma_{o i}\right)+\cup_{i} \cdot\left(\sigma_{o i}-\sigma_{i}\right)+\frac{-}{2}
$$

The inner surface temperature of the time steps (one hour) $\mathrm{j}=1,2 \ldots .8760$ is given by the solution (4) of the simple differential equation system (1) to (3)

$$
\theta_{o i, j+1}=\theta_{o i, j}+\left(\theta_{o i L I M, j}-\theta_{o i, j}\right) \cdot\left(1-\exp \left(\beta_{j} . t\right)\right)
$$

If the temperature is known at the time step $j$, the temperature at the time step $j+1$ can be calculated by a simple exponential time function. The heat capacity $\mathrm{C}_{\mathrm{L}}$ of the room air is approximately zero. The heat capacity of the inner storage mass $C_{i}$ and of the outside storage mass $C_{e}$ is depending on the penetration depth or the penetration time of the thermic signal ( $\lambda$ thermal conductivity, c specific heat capacity, $\rho$ density, $A_{O}$ inner or outer surface, $t_{s p}$ penetration time \{e.g. in Central Europe approximately the weather change time from 10 days $\}$ )

$$
C=\frac{1}{2} \cdot \sqrt{\frac{t_{s p}}{\pi} \cdot \lambda \cdot \rho \cdot c \cdot A_{o}}
$$

The heat transport terms are given by: $\mathrm{T}_{\mathrm{W}}{ }^{\prime}=\mathrm{U}^{\prime}{ }_{\mathrm{W}} \cdot \mathrm{A}_{\mathrm{W}}$ (transmission for walls and roofs without transition coefficients), $\mathrm{T}_{\mathrm{F}}=\mathrm{U}_{\mathrm{F}} . \mathrm{A}_{\mathrm{F}}$ (transmission for the windows including the transition coefficients), $\mathrm{S}_{\mathrm{W}}=\mathrm{a} . \mathrm{G} . \mathrm{A}_{\mathrm{We}}$ (indirect radiation transport through the walls and roofs, $G$ whole radiation loading, a absorption coefficient),

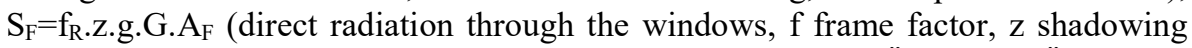
factor, g permeability of glass, $G$ whole radiation loading), $\ddot{U}_{\mathrm{i}}=\mathrm{h}_{\mathrm{i}} . \mathrm{A}_{\mathrm{Wi}}, \ddot{\mathrm{U}}_{\mathrm{e}}=\mathrm{h}_{\mathrm{e}}$. $A_{W e}$ (transition on the inner and outer surfaces, $h$ transition coefficient). L means the heat transmission value by the ventilation rate $\mathrm{n}_{\mathrm{L}}: \mathrm{L}=\rho_{\mathrm{L}} \cdot \mathrm{c}_{\mathrm{pL}} \cdot \mathrm{n}_{\mathrm{L}} \cdot \mathrm{V}_{\mathrm{L}}$. The dimensional units of these items are: $\theta$ in ${ }^{\circ} \mathrm{C}, \mathrm{T}_{\mathrm{W}}{ }^{\prime}, \ddot{\mathrm{U}}_{\mathrm{i}}, \ddot{\mathrm{U}}_{\mathrm{e}}, \mathrm{T}_{\mathrm{F}}, \mathrm{L}$ in $\mathrm{W} / \mathrm{K}, \mathrm{C}$ in $\mathrm{Ws} / \mathrm{K}, \mathrm{S}$ in $\mathrm{W}, \mathrm{J}$ in W.

The limit surface temperature $\theta_{\text {oiLIM,j }}$ and the written out indoor air temperature $\theta_{\mathrm{iLIM}, \mathrm{j}}$ in (9) contain only the transport terms, the radiation gains and the inner heat sources. The time coefficient $\beta_{\mathrm{j}}$ contains the transport terms and the heat capacities of the building parts (equations (6) to (8)).

$$
\begin{gathered}
\beta_{j}=\frac{-E_{j}}{2}-\sqrt{\left(\frac{E_{j}}{2}\right)^{2}+B_{j}} \\
E_{j}=\frac{\ddot{U}_{i}}{C_{i} \cdot\left(L_{j}+T_{F}\right)} \cdot\left(\frac{1}{\left.\frac{1}{\ddot{U}_{i}}+\frac{1}{L_{j}+T_{F}}\right)-\frac{T^{\prime}{ }_{W}+\ddot{U}_{e}}{C_{e}}-\frac{T^{\prime}{ }_{W}+\ddot{U}_{i}}{C_{i}}}\right. \\
B_{j}=\frac{T^{\prime}{ }_{W}+\ddot{U}_{e}}{C_{i} \cdot C_{e}} \cdot\left(\frac{1}{\frac{1}{\ddot{U}_{i}}+\frac{1}{L_{j}+T_{F}}}+\frac{\frac{1}{T^{\prime}}+\frac{1}{\ddot{U}_{e}}}{{ }^{\prime}}\right)
\end{gathered}
$$


Finally the indoor air temperature for each time step (1h) from $\mathrm{j}$ to $\mathrm{j}+1$ is given by equation (9). The total number of time steps is $8760 \mathrm{~h}$ for a year.

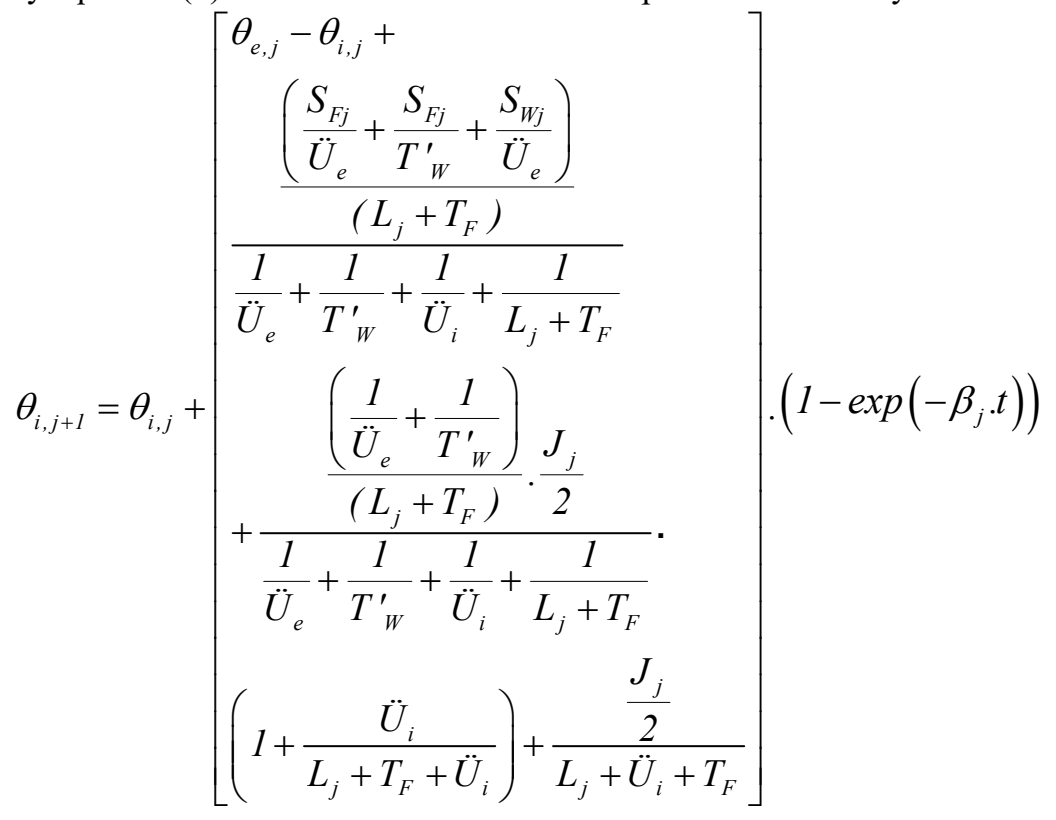

The solution (9) for the indoor air temperature contains all heat transport coefficients $T, \ddot{U}, L$, the solar radiation values $S$, the indoor heat sources $J$ and in $\beta_{\mathrm{j}}$ the heat storage coefficients $\mathrm{C}$ in logical and clear manner. The heating power $\mathrm{J}$ can be given manually or in dependence on the outside or inside climate. The same applies to the ventilation rate $\mathrm{n}$ and the shading $\mathrm{z}$. The intensity of the internal heat sources bases on the use of the internal space.

\section{Modelling of the moisture balances of the indoor room}

The moisture balances can be formulated like the heat energy balances. The driving potential is now the water vapour pressure. The moisture storage terms depend on the hygroscopicity $\left(\mathrm{w}_{\mathrm{h}}=\mathrm{dw} / \mathrm{d} \phi\right.$ slope of the hygroscopic isotherm) and the water vapour diffusion ( $\mu$-value) of the materials of the inner surfaces. The model for the determination of the room temperature can be transferred analogously to the calculation of the water vapor pressure or the relative humidity. The moisture model is comparatively easy, because no moisture is transported by transmission through the comprehensive construction (unless rain penetrates the building parts) and there is no "humidity radiation". The important variables (Fig. 4) are: actual vapour pressure $p_{D e}$, saturation vapour pressure $p_{S e}$ and relative humidity $\phi e$ for the outside and $\mathrm{p}_{\mathrm{Di}}, \mathrm{p}_{\mathrm{Si}}$ and $\phi \mathrm{j}$ for the inside, the moisture storage stream of the room air $\mathrm{dm}_{\mathrm{SpL}} / \mathrm{dt}$, of the walls or of the furnishings $\mathrm{dm}_{\mathrm{Spi}} / \mathrm{dt}$, the airborne moisture flow $\mathrm{dm}_{\mathrm{L}} / \mathrm{dt}$, the moisture transfer flow $\mathrm{dm}_{\mathrm{U}} / \mathrm{dt}$ and the moisture flow of the inner sources $\mathrm{dm}_{\mathrm{QU}} / \mathrm{dt}$.

$$
\frac{d}{d t} m_{S P L}=C_{L F} \cdot \frac{d}{d t} p_{i} \quad \text { Moisture flow stored from the room air }
$$




$$
\begin{gathered}
d t \quad{ }^{\mathrm{s} t} \quad{ }^{r l} d t^{* o} \\
\frac{d}{d t} m_{L}=\frac{V_{L} \cdot n_{L}}{R_{D}} \cdot\left(\frac{p_{e}}{T_{e}}-\frac{p_{i}}{T_{i}}\right) \text { Moisture flow transmitted by ventilation rate } \mathrm{n}_{\mathrm{L}} \\
\frac{d}{d t} m_{\ddot{U} i}=\ddot{U}_{i F} \cdot\left(p_{o i}-p_{i}\right) \quad \text { Moisture flow delivered and recorded from walls } \\
\frac{d}{d t} m_{Q U}=m_{p t t} \cdot V_{L} \quad \text { Moisture flow submitted from internal moisture sources }
\end{gathered}
$$

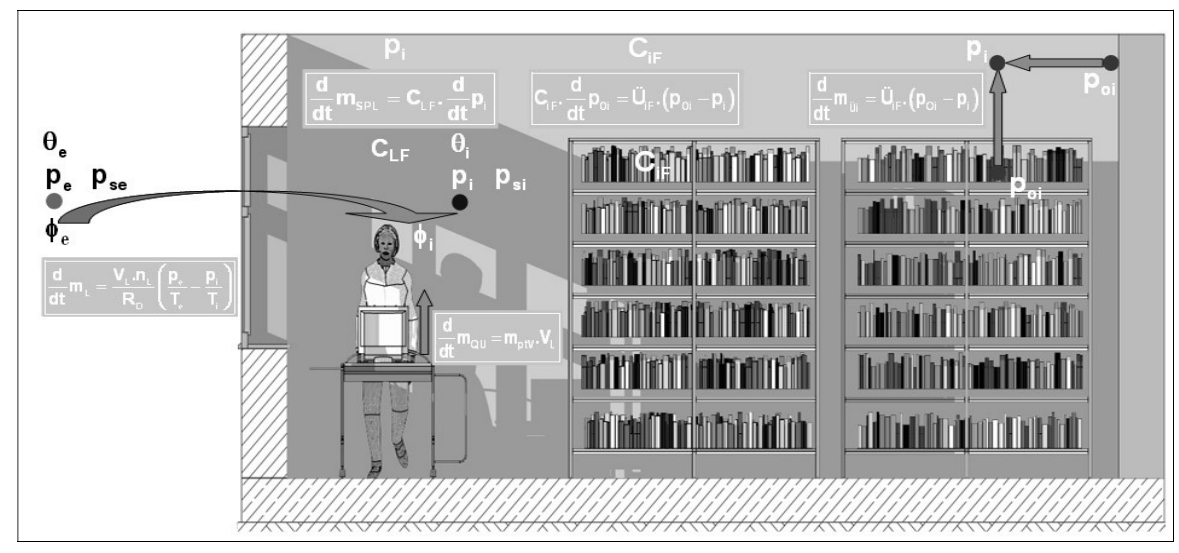

Fig. 4. Moisture balances of the interior of the house.

The moisture flow model (15) to (17) can be formulated analogously the energy flow model in section 2 (equations (1) to (3)). The moisture flow through the wall can be neglected, because the hygric transmission term is approximately zero.

$$
\frac{d}{d t} m_{T}=0
$$

Indoor air humidity balance

$$
C_{L F} \cdot \frac{d p_{i}}{d t}=\frac{V_{L} n_{L}}{R_{D}} \cdot\left(\frac{p_{e}}{T_{e}}-\frac{p_{i}}{T_{i}}\right)+\ddot{U}_{i F} \cdot\left(p_{o i}-p_{i}\right)+m_{p t V} \cdot V_{L}
$$

Interior surface moisture balance

$$
C_{i F} \cdot \frac{d p_{o i}}{d t}=\ddot{U}_{i F} \cdot\left(p_{o i}-p_{i}\right)
$$

Instead of the temperature the water vapour pressure acts as the driving potential. The moisture balance equation on the outer surface is not relevant for the indoor air humidity and therefore it can be omitted (15). However, the moisture storage capacity of the indoor air $\mathrm{C}_{\mathrm{LF}}$ in $\mathrm{kg} / \mathrm{Pa}$ in the moisture balance equation for room air (16) must be considered. It follows from the gas equation, $R_{D}=462 \mathrm{Ws} / \mathrm{kgK}$. 


$$
C_{L F}=\frac{V_{L}}{R_{D} \cdot T_{i}}
$$

Analogous to the specific heat ventilation flows $\mathrm{L}$ are the specific (now related to the vapour pressure) ventilation moisture flows $\mathrm{L}_{\mathrm{Fi}}$ and $\mathrm{L}_{\mathrm{Fe}}$ in (19)

$$
L_{F i}=\frac{V_{L} \cdot n_{L}}{R_{D} \cdot T_{i}}, \quad L_{F e}=\frac{V_{L} \cdot n_{L}}{R_{D} \cdot T_{e}}
$$

The moisture transfer value in (16) and (17) from room air /inner surfaces in $\mathrm{kg} / \mathrm{sPa}$ is given by $(20)\left(\mathrm{h}_{\mathrm{c}}\right.$ thermic transition coefficient by convection):

$$
\ddot{U}_{i F}=7,9 \cdot 10^{-9} \frac{\mathrm{kg}}{\mathrm{Pa}} \frac{\mathrm{K}}{\mathrm{Ws}} \cdot h_{c} \cdot A_{O i}
$$

The humidity flow of the sources $\mathrm{dm}_{\mathrm{Qu}} / \mathrm{dtdV}=\mathrm{m}_{\mathrm{ptV}}$ in $\mathrm{kg} / \mathrm{m}^{3} \mathrm{~h}$ in (16) is released completely (not just half like in (2)) into the air. Moisture is not transferred by radiation. In the moisture balance equations the terms $\mathrm{T}$ and $\mathrm{S}$ are deleted. The moisture storage in the enclosure surface area or furnishings $\mathrm{C}_{\mathrm{iF}}$ in $\mathrm{kg} / \mathrm{Pa}$ is depending on the penetration depth of the hygric signal $\left(\mathrm{t}_{\mathrm{sp}}\right.$ the storage time, $\delta_{\mathrm{L}}=1.85 .10^{-10} \mathrm{~S}$ vapour conductivity in air), compare the thermic storage capacity equation (5)

$$
C_{i F}=\frac{1}{2} \cdot \sqrt{\frac{t_{s p}}{\pi}} \cdot \sqrt{\frac{\delta_{L}}{\mu} \cdot \rho_{W} \cdot \frac{w_{h}}{p_{s}}} \cdot A_{o i}
$$

The balance equations (17) are inserted into the equation (16), which leads to a simple differential equation for calculating the time course of the water vapour pressure $\mathrm{p}_{\mathrm{oi}}$ on the inner surface and later for the room air $\mathrm{p}_{\mathrm{i}}$. The solution for the $(j+1)$-st (selected here again a total of 8760 hours time steps for a year) period is (compare (9)).

$$
p_{o i, j+1}=p_{o i, j}+\left(p_{o i, L I M, j}-p_{o i, j}\right) \cdot\left(1-\exp \left(-\beta_{F j} \cdot t\right)\right)
$$

Herein means $\mathrm{p}_{\mathrm{oi}, \mathrm{LIM}, \mathrm{j}}$, the water vapour pressure at the surface after an infinitely long time, $p_{o i, j}$ is the pressure at the beginning of the $j$-th time step, $p_{o i, j+1}$ is the pressure at the end of the $j$-th time step and $\beta_{\mathrm{Fj}}$ is the time constant for the humidity adjustment within the $\mathrm{j}$-th time step.

$$
\begin{gathered}
p_{o i, L I M, j}=p_{e, j}+\frac{m_{p t V} \cdot R_{D} \cdot T_{i}}{n_{L j}} \\
\beta_{F j}=\frac{1}{C_{i F}} \cdot\left[\frac{1}{\frac{R_{D} \cdot T_{i}}{V_{L} \cdot n_{L j}}+\frac{1}{\ddot{U}_{i F}}}\right]
\end{gathered}
$$

Equation (24) corresponds to equation (6) in chapter 2. To determine the partial pressure of water vapour of the outside air at the time $j$ or time $j+1$ and the saturation 
pressure must be calculated depending on the outside air temperature (see column 2 in table 1)

$$
p_{s e, j}=610,5 .\left(\begin{array}{l}
e^{\frac{17,26 \cdot \theta_{e, j}}{273,3+\theta_{e, j}}} \cdot \Phi\left(\theta_{e, j}\right)+e^{\frac{21,87 \cdot \theta_{e, j}}{265,5+\theta_{e, j}}} . \\
\Phi\left(-\theta_{e, j}-10^{-6}\right)
\end{array}\right)
$$

The step function $\Phi$ in (21) is 1 for positive arguments and 0 for negative arguments. With the measured values of the outside relative humidity $\phi_{\mathrm{ej}}$ (see column 3 in table 1) follow the vapour pressure

$$
p_{e, j}=\phi_{e, j} \cdot p_{s e, j}
$$

Finally the water vapour pressure of the room air is given by:

$$
p_{i, j+1}=\frac{p_{o, j+1} \cdot \ddot{U}_{i F}+p_{o, j+1} \cdot \frac{V_{L} \cdot n_{L j}}{R_{D} \cdot T_{i}} \cdot 3600}{\frac{V_{L} \cdot n_{L j}}{R_{D} \cdot T_{i}} \cdot 3600+\ddot{U}_{i F}}
$$

From the water vapour pressure (27) and the saturation pressure (25) in the room the second major component of indoor climate, the inside relative humidity, at the time $\mathrm{j}+1$ follows

$$
\phi_{i, j+1}=\frac{p_{i, j+1}}{p_{s i, j+1}}
$$

From the values for the air humidity at time $\mathrm{j}$, the values can be calculated by a simple loop for the time $\mathrm{j}+1$. No iteration is required. The moisture sources $\mathrm{m}_{\mathrm{ptV}}$ can be given manually or in dependence on the outside or inside climate. The same applies to the ventilation rate $\mathrm{n}$. The intensity of the internal moisture sources bases on the use of the internal space.

\section{CLIMT Example: „Golden hall“ in Nürnberg}

The equations (9) and (22) with (28) have been written ad first in MATHCAD and than in $\mathrm{C}++$ and they form the central part of the CLIMT program. For the room geometry (compare Fig. 5) and the all room using parameters are to design simple input masks. The outside climate (in this chapter the measured file Nürnberg 2015) will be supplied by the CLIG program. The program CLIMT is user friendly and suitable for the common professional use. Up to now following test houses have been investigated: a so called floating house in South Brandenburg from the BTU in Cottbus (built 2008) [1], a library archive in Magdeburg (built 2014) [1] and the "Golden hall" below the "Zeppelin-terrace" (Figs. 6 and 7, in renovation since 2015 by the Hochbauamt Nürnberg) [4]. 


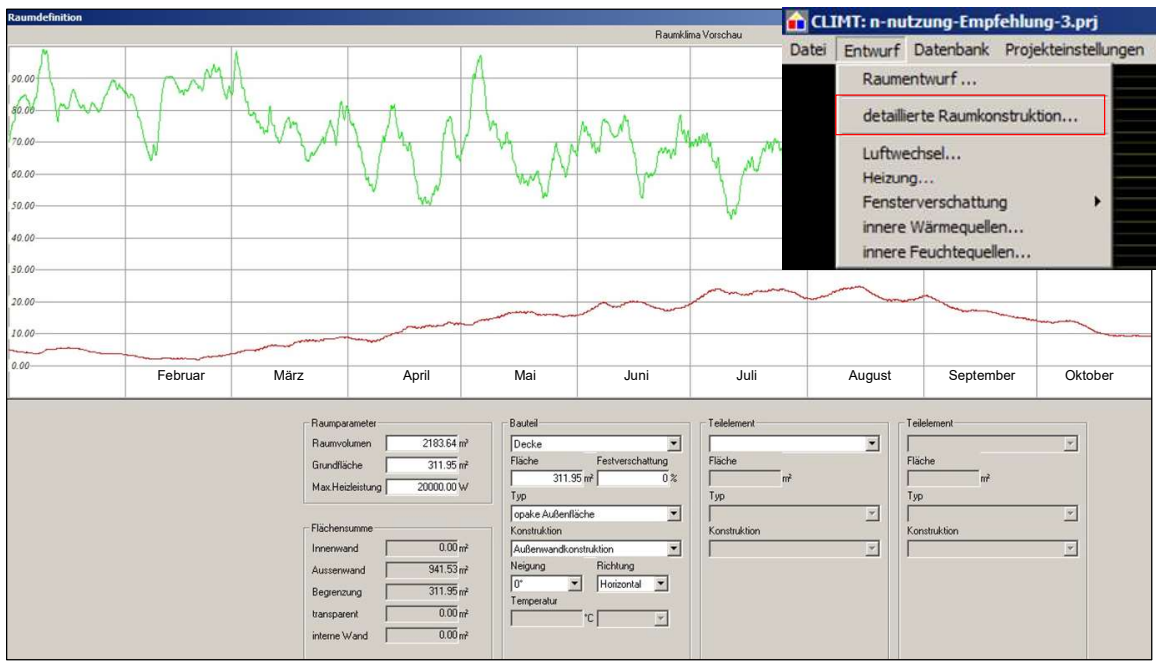

Fig. 5. Example for the CLIMT input mask (detailed room structure), mini grafik of temperature (red) and relative humidity (green) and an overview of the other input masks (CAD input, ventilation, heating, shadow of windows, thermic sources, hygric sources).

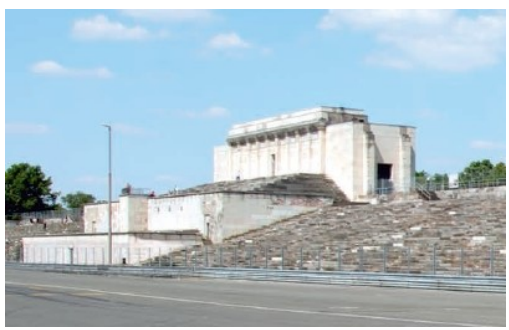

Fig. 6. Ruin of the Zeppelintribüne Nürnberg.

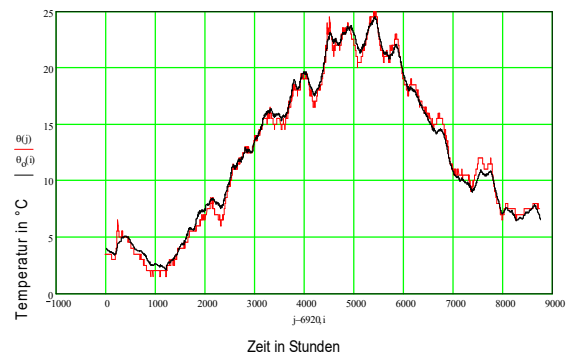

Fig. 8. Indoor air temperature 2015, measured (red), calculated by CLIMT (black) in the Golden hall.

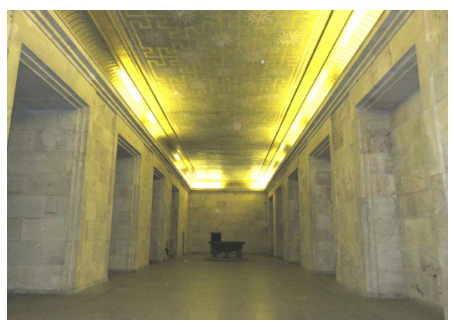

Fig. 7. „Golden hall “ below the terrace length $36.6 \mathrm{~m}$. width $8.6 \mathrm{~m}$, heigth $7 \mathrm{~m}$.

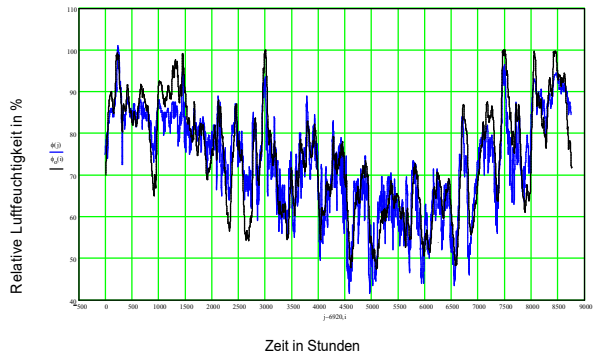

Fig. 9. Indoor air relative humidity in 2015 , measured (blue), calculated by CLIMT (black).

The measured and the calculated values for the actual situation (measured climatic file Nürnberg 2015, without visitors, without heating system) agree very well. In the future this "controversial monument" should be used for a limited number of visitors. For these purposes a photovoltaic equipment completed by a simple electrical radiation heating system (panel radiators a $600 \mathrm{~W}$ ) will be installed.. 
The temperature during the wintertime should be higher than $8^{\circ} \mathrm{C}$. The situation during the summer is not critical because the monument is a very heavy building. The detailed legend of the Fig. 10 (screen chart of the CLIMT program) shows the indoor climate under the proposed conditions. By way of comparison all temperature graphs in the mentioned test houses have been calculated also by the TRNSYS program [5] with a good accordance. However the moisture tool in TRNSYS is physical incorrect and therefore it has not been used.

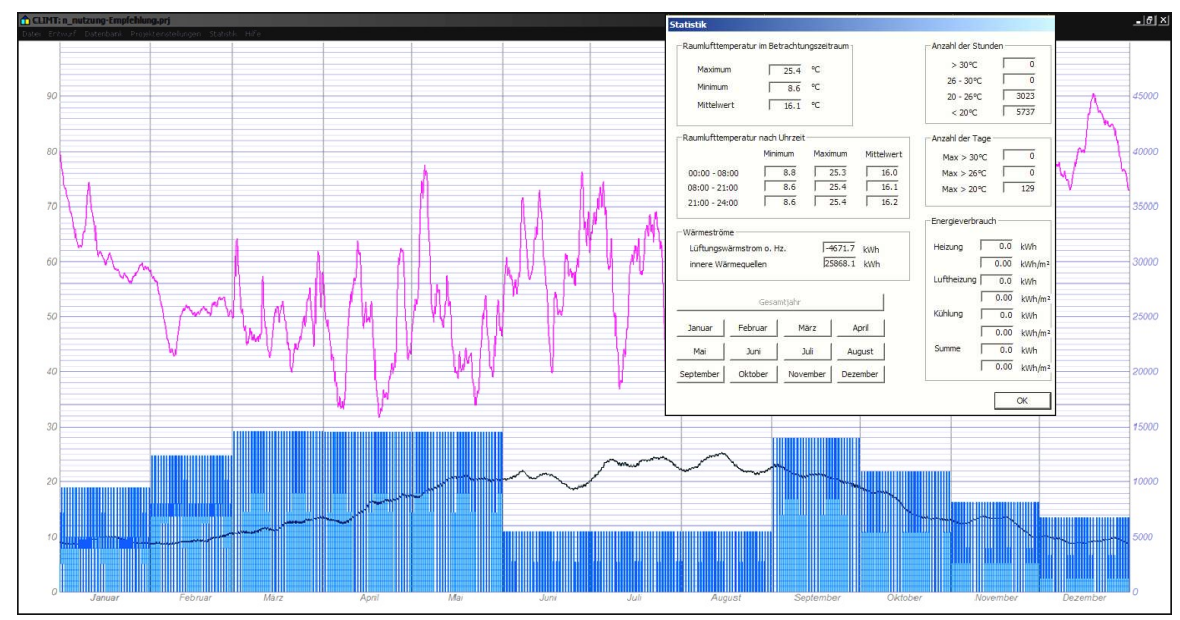

Fig. 10. Indoor climate in the „Golden hall“ in Nürnberg under condition of use prognosticated by CLIMT. Relative humidity in \% (magenta), temperature in ${ }^{\circ} \mathrm{C}$ (black), left coordinate axis. Maximum temperature $25.4^{\circ} \mathrm{C}$, minimum temperature $8.6^{\circ} \mathrm{C}$, outdoor climate Nürnberg 2015. Conditions of use: 40 people a $100 \mathrm{~W}$ for four times one hour daily, light intensity during this time $1600 \mathrm{~W}$, photovoltaic heating system (monthly mean value as step function, active only during the day, excluding June to August), additional electrical heating power from $9 \mathrm{am}$. to $6 \mathrm{pm}$ by day (January $6 \mathrm{~kW}$,February $4 \mathrm{~kW}$ ) and from $3 \mathrm{am}$ to $9 \mathrm{am}$ by night.(January and February $3 \mathrm{~kW}$ ), (blue), right coordinate axis, whole additional electrical heating energy $3336 \mathrm{Wh}$., ventilation rate November to February $0.05 / \mathrm{h}$, March to October $0.2 \mathrm{~h} / \mathrm{h}$. The mask shows the thermic threshold values in February.

\section{References}

1. W. Willems (Hrsg.), Lehrbuch der Bauphysik, P. Häupl Kapitel Klima S.307410, 8. Auflage, Springer Viehweg Verlag (2017)

2. A. Bishara, P. Häupl, F. Hansel, Model and program for the prediction of the indoor air temperature and indoor air relative humidity, Journal of Building Physics, SAGE Publications, Thousand Oaks CA USA, September (2014)

3. P. Häupl, F. Hansel, Klimagenerator CLIG zur Gebäude- und Bauteilsimulation, Bauphysik, H. 3, S. 175- 190. Ernst \& Sohn Verlag, Berlin (2017)

4. E. Anlauft, Sanierung der Zeppelinterrasse in Nürnberg (unpublished) Hochbauamt, Nürnberg (2015)

5. S.A. Klein, TRNSYS a Transient System Simulation Program, Madison USA, (2000) 